arise again in connection with United Nations responsibilities for the administration of South West Africa.

The second question is whether the General Assembly itself may take enforcement-like action. Again it is clear that the General Assembly cannot order enforcement action. But you are all aware of the issue as to whether an Assembly recommendation may form the basis for such action by Member States. The United Nations action in Korea was in response to a Security Council "recommendation" rather than a "decision" and the Uniting For Peace Resolution was originally intended, and initially applied, to enable a similar action in response to General Assembly recommendations. It was contended that while primary responsibility for the maintenance of international peace and security is vested in the Security Council, a residual authority must lie with the General Assembly when the Security Council is unable to take action. Subsequently of course, the Uniting Fror Peace Resolution has been used for peace-keeping operations undertaken with the consent not only of participating states but also of the state or states directly concerned. Even these consensual operations are the subject of challenge and controversy. However, the General Assembly continues to adopt at each session by large majorities resolutions calling on states to apply economic measures similar to those described in Article 41 and in resolutions on Southern Rhodesia has called on the United Kingdom, as the administering authority, to take all necessary measures "including in particular the use of force."

I have not attempted to draw conclusions, but merely to sketch the background and pose a few illustrative problems. I would suggest, however, that questions of implementation and enforcement of decisions of international organizations are central to the larger question of organizing our international community for survival in this nuclear age. I would also submit that the problems are more a dearth of will than of ways. As has been said so frequently of sanctions under the League, it was not so much that they were tried and found wanting, but that they were found difficult and not tried at all. One may wonder how different the world might be today if the United Nations had grappled successfully with these problems in the first days of its creation. Fortunately, it is not yet too late.

\title{
THE ENFORCEMENT OF INTERNATIONAL JUDGMENTS
}

\section{BY W. M. Reisman}

\section{Yale Law School}

Judgment enforcement is not a problem unique to international law. That persistent ontological assumption of the law-that a judgment is a decision-obscures the fact that statements made in a court room are simply words-signs and symbols. These words may indeed carry some potential for compulsion. They may activate certain inculcated pre- 
dispositions in the target audience to which they are directed and the audience may, as a result, regulate its collective behavior in conformity with the policy prescription of the judgment. But whether, to what degree and under what circumstances words will contribute toward realization of the desired social goal will depend upon numerous contextual factors.

Judgment enforcement generally refers to a sequential phase after a judgment has been delivered and before its pronouncement has been realized in terms of concrete value allocation. We tend to conceive of enforcement as a process discrete from the adjudicative proceedings which precede it. For this reason, there has been some apathy among legal specialists to give enforcement, whether on the municipal or the international level, any detailed consideration. But law, in any meaningful social sense, must connote effective as well as authoritative decision. Hence, decision, in all its diverse functions, must constantly consider enforcement and enforceability. Approached from this perspective, it will become readily apparent that the process of enforcement does not begin after a judgment has been delivered; it begins with the very initiation of the case. Under certain circumstances, it may be a critical factor in deciding whether to initiate the judicial process at all. It will also become apparent that the process of judgment enforcement is no more mechanical than the process of judicial application. Each of its component sequences presents difficult and complex policy choices.

In developing a socially relevant and useful conception of judgment enforcement, then, we must emphasize the essential integrality of all decision functions. Judgments alone do not make law. The procedures by which policy is clarified, authorized and realized, in short, in which decisions are made, are executed in a number of different functions. The court phase represents at best one of them. If that phase is not executed after consideration has been given to all relevant preceding and subsequent phases, adjudication will be no more than an exercise in pretended power.

In an arena of a relatively low degree of organization, the objective of an enforcer cannot restrict itself to the mere realization of a particular judgment. Of equal and, at times significantly greater importance, is the constitutive aspect of the problem. The constitutive goal is the creation of conditions facilitating voluntary compliance with and, where necessary, economic and expeditious enforcement of international judgments. Whether this means the creation of an international enforcement mechanism, comparable to municipal institutions, such as that envisaged in Charter Article 94(2), or whether radically different structures, dictated by power allocations in the world arena, are preferable, the point of emphasis remains. At each phase of the process of enforcement, decisionmakers must constantly consider both short-range enforcement requirements as well as the long-range constitutive impacts of their decisions.

Doctrinal disquisition of enforcement takes the concept of "finality" as its touchstone for goal consideration. Judgments are to be treated 
as irrevocably final because "interest reipublica ut sit finis litium." I suggest that this traditional formulation is too ambiguous and unrefined to express the key policy considerations involved in enforcement. The minimum objective of public order is not finality but stability. Finality is one of a number of strategies for achieving stability, and in situations in which insistence on finality would have destabilized political order, alternate instruments for achieving stability have been sought. Hence the preferable normative statement of the enforcer would be that the minimum objective of enforcement is to achieve the realization of certain value goals, at the same time maintaining an optimum level of stability.

As a description of past trends, "finality" is equally unrefined. An empirically verifiable definition of "finality" would posit that finality in any case or line of cases is the degree of purposive community force applied to sustain a judgment and resulting in the realization of the terms of that judgment without material diminishment. It is clear that degree of finality, so understood, has varied widely according to the type of case, the circumstances and the parties. Of particular relevance is the fact that the judgments which have not been "finalized" have not invariably been held to be breaches or deviations from the law. The point is clear: the goals of enforcement transcend any particular case. In addition to the preference for realizing that decision, enforcers consider the effects of enforcement on minimum stability of the public order system involved as well as the longer term effects on constitutive enforcement.

The student of international enforcement can most profitably approach his subject not in a post-adjudicative phase, but at the earliest point in social interaction when a number of participants make conflicting claims to a limited number of values. In an unorganized arena, with relatively unrefined institutional practices, the modalities by which participants choose to reconcile claims and reach effective decisions are options rather than predetermined patterns. The realist's notion that force, as the ultima ratio, will be employed by the stronger party is as inaccurate as it is oversimplified. In the vast majority of disputes, modalities manifesting more persuasive than coercive features are resorted to ; in certain rare instances, adjudication is chosen. It is a rather grim comment on the degree of realism of research in international law that relatively little hard data is available on why states have or will submit to adjudication.

Fnforcement consideration should begin in the preadjudicative phase, a negotiating or bargaining process. Words in the compromis providing a reinforced finality are not an adequate acquittal of this demand. Bargaining theorists have demonstrated the range of possibilities in preagreement phases for structuring effective enforcement procedures into the total agreement context. Some of these can be applied to the negotiation of a compromis or submission. We will consider them briefly at a later stage. The reluctance of one party to commit itself to such structuring is some indication of its probable reaction should it lose its case. Hence the initiating party might reformulate the content of the submission, undertake unilateral enforcement structuring, or turn to another modality 
of conflict resolution rather than adjudication. The converse is equally relevant. A government which anticipates that it will be unable to comply, because of probable internal opposition or, specifically, the recalcitrance of a branch of government involved in the compliance process, should not, under those conditions, submit to adjudication.

Once the adjudicative process has come into operation, the primary capacity to consider and affect ultimate enforcement procedures is tranferred to the judges or arbitrators. Insofar as they are sensitive to enforcement considerations, they can introduce various mediant and outcome effects through a number of devices. The refusal to seise jurisdiction in a preliminary phase can, for example, be employed if it is highly probable that one party will not comply with a judgment and that coercive enforcement will be either unfeasible or unattainable. A number of ICJ opinions can be construed as applications of this strategy. In at least two controversial cases, jurisdictional disseisure was deferred until a subsequent phase of adjudication. This is a practice which can be justified under certain circumstances by exigency, but one which seems to excite more problems than it lays to rest. More creative responses involve integration within a judgment of palatable and unpalatable elements such that the party considering repudiation of the decision will be deterred by the prospect of losing as much as it gains. In addition to integrative solutions, the verbal formulation of a judgment can at times soften a material loss; conversely, a bluntly worded judgment, though precipitating longe-range prescriptive effects, may force a litigant to repudiate the decision. The point to be emphasized is that judges and arbitrators can and, I submit, should be active agents of enforcement during the judicial process.

The conventional focus of international as of municipal judgment enforcement has been in the post-adjudicative phase. Anterior planning may, to an extent, deemphasize this phase, yet the ultimate test of effective enforcement will be tried here. Hence one must consider the components of enforcement in this critical phase.

Enforcement refers to the transformation, by community means, of authoritative pronouncement into controlling reality. Organized communities enforce their authority in two ways. By direct enforcement, they supervise the physical transfer of what was decreed in authoritative decision. By indirect enforcement they impose sanctions on the miscreant in order to persuade him to comply with community norms. Direct enforcement is frequently substitutive, i.e., the community arranges for the physical transfer of an equivalent in value to the original object of decision.

The community may resort to indirect enforcement because it is simply incapable of enforcing its authority directly. The assets in question may be out of jurisdiction or intangible, hence not subject to seizure and transfer. They may have been consumed in delicto; hence sanctions demonstrate community opprobrium prospectively. In other instances, direct enforcement is possible, but the community chooses indirect instru- 
mentalities for other reasons. They may be more economical, more expeditious or may encounter less resistance.

International enforcement theories were forged when the interaction between nations was relatively low. The assets of any one state were usually found within its territorial bounds. Since direct enforcement would have required physical intervention, indirect enforcement alone seemed feasible. Massive changes in the international context have rendered this line of thinking anachronistic. As the level of international interaction has risen and as governmental programs have broadened, an enormous quantity of state assets are found abroad. Contemporary enforcement theory should concentrate on the hitherto neglected possibilities of direct and substitutive enforcement.

In an organized community, the expectation of the effectiveness of enforcement mechanisms is a factor inducing compliance. Enforcement becomes a "self-fulfilling prophecy." In an unorganized polity, in which the record of enforcement is erratic, active measures are required in a larger number of cases. If these measures are successful, expectations of effectiveness are generated, permitting enforcement machinery subsequently to fulfill its function by symbolic presence rather than by active intervention. If the measures are unsuccessful or equivocal, voluntary compliance will remain low. The impact of success or failure on expectations of future effectiveness emphasizes the exigeney of care in the very choice of cases for enforcement.

In an organized community, power is concentrated in an authorized and centralized enforcement agency: the sheriff, and, on the macronational scale, the executive branch. Jeremiads about the unenforceability and "nonlaw" quality of international law stem, in great part, from the fruitless search for a comparable centralized, organic international sheriff. Such an institution does not exist. The creation of an organic, international sheriff is a long-range goal. In the interim, a functional system of international enforcement can be an instrument for preserving current minimum order and for laying the groundwork for future institutionalization of the world community.

A functional system is based on the political-legal elements at play in an enforcement process: community authority and effective power. The relevant social context is scrutinized and combinations of authority and effective power, which can act functionally as an enforcement system, are arranged. From the spectrum of possible relationships, that combination which can enforce most economically, yet poses the least jeopardy to international peace, is chosen.

The functional system is applied, almost intuitively, by the lawyer seeking to gain judgment execution in another jurisdiction. The lawyer who has gained a judgment in province $A$, but cannot execute there, will seek execution in a province having control over the assets of the judgment debtor. If provinces $\mathrm{B}, \mathrm{C}$, and $\mathrm{D}$ each have control of adequate assets, the choice of an enforcing forum will turn on other factors: attitudes toward foreign judgments, complexity or simplicity of procedure, bond 
requirements, geographical distance et cetera. One province will present the most attractive opportunities for enforcement. International enforcement is more complex. Many of the factors which were predictably stable in a municipal arena manifest heightened variability and sensitivity to political crisis in international law. Hence numerous factors which municipal counsel need not consider must be scrutinized systematically by international lawyers.

A functional method of enforcement which adapts and systematizes the intuitive approach of the municipal lawyer in extra-jurisdictional enforcement is presented here. The subject for enforcement is a hypothetical ICJ decision. Primary attention is given to direct and substituted enforcement, though the possibilities for indirect enforcement are examined cursorily. This model has two objectives: to secure compliance with IOJ judgments and at the same time to generate expectations of an effective international enforcement system, favorable to the ultimate creation of a centralized international enforcer.

The functional model of enforcement comprises four elements: the target state, which has lost the judgment; the enforcers; the power bases of enforcers applicable to the enforcement problem at hand; and the strategies to be employed. An abbreviated model of this sort can be no more than a rough outline and a high-point indicator of an ever-shifting social context. While we can speak in general of more or less homogenous collectivities, any more refined examination of past trends or future probabilities in judgment enforcement will require a more detailed and comprehensive map of variables. Some writers have tended toward a general characterization of a "law habit" as an indicator of enforceability. But the so-called law habit is not transitive.

Individuals will be more or less predisposed to participate in the implementation of a specific judgment according to such factors as who was involved in making the decision, whom does it affect, what is the extent of shared or divergent perspectives of all participants, what are the consequences of the decision in terms of value shaping and sharing, under what circumstances was the decision taken-geography, time and crisis-what are the aggregate power positions of the authoritative enforcers and those committed to supporting the decision as opposed to those opposing, by what means, including the form of communication was the decision taken, what are the probable value outcomes of the decision, and what are its prospective effects. Level of external crisis must also be considered, for a threat to group security or integrity from without can change perspectives markedly, extending the individuals conception of self-interest to include the entire group. All of these factors are perceived with differing degrees of clarity by participants themselves and the diverse impressions which they absorb are fed back and become an element of enforceability.

Let us, then, consider the model.

1. Enforcers: Potential enforcers include general international organizations, functional agencies, regional organizations, nation states acting 
jointly or severally and unofficial groups of individuals. Not all of these entities have direct control over the assets of the target state. Nevertheless, a state with control will frequently find it easier to act if it is "directed" by an authoritative organization. A strategy of enforcement may coordinate a controlling state and a noncontrolling but highly authoritative organization. For example, if certain assets of the target state are in republic $X$, its government might find it inexpedient to transfer these assets to state $Y$, the judgment-creditor, solely on the basis of $Y$ 's request. The target would interpret the act as hostile and might retaliate. It is recommended that $Y$ move that an international organization "enjoin" $X$ to transfer the assets, thereby permitting $X$ to participate in enforce-

- ment without bearing primary responsibility. If the target state or its ally were capable of vetoing an injunction in a general organization, $\mathrm{Y}$ is urged to seek a regional or specialized organization to which the target does not have access.

The subjectivities of the elites in potential enforcing polities are of major significance. Do elites tend to identify themselves with the target or the creditor state? Do they commit themselves to an international program which favors peaceful resolution of disputes? Does the judgment in question offend their own public policies? These factors are indicators of the willingness (as opposed to capacity) of third-party states to participate in enforcement.

2. Power Bases: Power bases of enforcers divide into authority and effective power. The latter is expressed in military and economic might. A community authorizes its sheriff to implement pronouncements and vests in him enough effective power for the task. The felicitous conjunction of authority and control is rarely found in one entity in international law. Certain organizations enjoy a general mandate to enforce, but have neither direct control over assets nor the capacity to acquire it. Effective power is primarily vested in states. In exceptional cases, it is found in functional organizations. Ideally, enforcement is compounded of both authority and control; consequently, entity combinations must be forged.

The conventional combination consists of a directive from an authoritative organization to a controlling organization or state. Unfortunately, applications for enforcement directives in the United Nations can be blocked. Directives from regional or functional organizations have a higher probability of success, though their judgment-enforcement authority is more tenuous. Where recommended combinations are unfeasible, joint or unilateral action must be pursued. Depending upon the context, such actions may acquire an ad hoc authority.

3. Strategies: The Charter sets out a spectrum of sanctions for indirect enforcement, but there is no comparable enumeration of techniques for direct or substituted enforcement. In fact, the world community's arsenal is well stocked with such techniques : attachment, garnishment, liens, freezing of assets, restrictive licensing, termination of aid et cetera. Sovereign immunity, which is likely to be invoked as a defense, is subservient to the 
duty to comply. It is not an absolute right; immunity is granted to members of the international community who evidence capacity and willingness to fulfill their obligations. Just as immunity from execution is not granted to an unrecognized state, it should not be accorded to a delinquent state. Much of the doctrine and practice of immunity hinges upon implications of reciprocity and retaliation. Therefore, immunity should be pierced in fora insusceptible to retaliation. If the judgmentcreditor, for example, pursues a strategy of indirect enforcement aimed at a state-owned ship of the target, attachment proceedings should be initiated in a port of call of a state which does not send its own ships to the target state.

The contemporary problem in indirect enforcement is the lawfulness of strategies. The unilateral querre d'execution was lawful, under certain circumstances, until 1945. The subsequent effect of Charter Article 2(4) is ambiguous. If it is not construed as an absolute prohibition, then only unlawful use of force is proscribed. Given the Charter's commitment to adjudication, coercive judgment enforcement might be lawful. The criteria of a valid querre d'execution would be (1) exhaustion of all possibilities of direct enforcement, (2) use of force commensurate with the objective, (3) compliance with the laws of war, (4) a context showing little likelihood of escalation. Use of the military strategy should, of course, come under the aegis of an authoritative organization whenever possible.

Some of the disillusionment with economic sanctions can be traced to a failure to clarify objectives. The economy of the target is rarely so dependent upon external economies that such sanctions could strike its industrial base with the decisive impact of aerial bombing. Not infrequently indiscriminate economic sanctions have strengthened rather than weakened the target. Economic strategies must be sharply honed to a particular purpose. If, for example, political-economic analysis of the target reveals that a wealth elite, with access to political power, can be severely damaged by a particular sanction, that sanction alone should be used in order to motivate the elite to pressure its government to comply. Carefully planned sanctions may bring about compliance without the dysfunctional results of the total embargo.

Five possible applications of the proposed enforcement system will be briefly sketched. Attention is focused on the range of enforcers rather than on the target. Potential combinations of authority and effective power are designated where appropriate.

1. General Organizations: Article $94(2)$ of the Charter of the United Nations provides that, in case of noncompliance with an ICJ judgment,

... the other party may have recourse to the Security Council which may, if it deems necessary, make recommendations or decide upon measures to be taken to give effect to the judgment.

In San Francisco, Cuba had proposed that the Statute be amended to allow a judgment-creditor to appeal total or partial noncompliance to the Council; the Council would then be obliged to adopt measures neces- 
sary for execution. Opponents of the amendment argued that a state would have recourse to the Council even without the amendment, in accordance with Chapters VI and VII of the Charter. This argument failed to dissuade Cuba and its supporters, since it conditioned enforcement action on a finding of threat to or breach of the peace; this circumstance, however defined, need not follow noncompliance. A compromise solution, Article 94(2), permitted recourse to the Council but made its subsequent enforcement action discretionary.

The fundamental ambiguity of Article 94 lies not in itself but in its relationship with the rest of the Charter. Security Council decisions may commission armed force or measures short of it only if peace is threatened. Clearly not every act of noncompliance constitutes an imminent threat to the peace. Were Article $94(2)$ an independent form of action, bypassing the need for a finding of a threat to the peace, it would have enormous constitutional and enforcement significance; on the juridical level, at least, it would make the United Nations a real international enforcer. The matter has not been clarified by doctrine or practice. These as yet inextricable difficulties and the inordinate power of the permanent members of the Council suggest that the United Nations cannot function as the world's sheriff.

2. Functional Organizations: Functional agencies linked to the United Nations have committed themselves to assist the Security Council in the execution of Chapter VII of the Charter. The reluctance of many of the agencies to oblige themselves is reflected in their qualified duty to support in many of the Special Agreements. In certain instances, a directive from the Council does initiate automatic sanctions within the agency's operational arena. The economic agencies, which have control over assets of states and which hence can enforce by direct substitution, retained a discretion as to whether and by what means they will implement Security Council directives.

A Council directive would accord a high authority to agency enforcement and, at the same time, shift the onus of primary responsibility. It may also be possible to bypass the Council and undertake enforcement directly through the agencies. In the economic agencies, for example, every member-state has a "current account" in gold and national currency. The judgment-creditor might move the agency to attach these funds or to transfer target funds to the account of the creditor. Such a strategy can anticipate resistance from the agencies. From their point of view, national currency is their working capital. Under certain circumstances, however, they might be persuaded to view the matter otherwise. If, for example, the target state announced that it intended to withdraw, the currency would change character; the agency might be less reluctant to transfer it to the account of the judgment-creditor. It might also be persuaded to cooperate if it were probable that mere preliminary moves to attach would impel the target to comply voluntarily. The agencies have an aversion to the politicization of their activities, hence they might be exhorted to initiate an interpleader by paying the money into Court. 
Finally, although the agencies enjoy a strong procedural immunity, there may be some possibility of municipal court action against the funds they hold.

3. Regional Organizations: The political interdependence which frequently precedes the constitution of regional organizations makes a regional state quite vulnerable to the concerted action of its neighbors. Thus, in the recent Honduras-Nicaragua border war, peripheral pressure from other OAS members brought the disputants to the Hague and ultimately secured voluntary compliance. In the Algeria-Morocco border war of 1963, efforts of the OAU brought the parties to arbitration and continued until there was compliance with the award. Thus, judgmentcreditors may initiate diplomatic activity within a regional organization with the specific aim of mobilizing its aid in enforcement. Notable Commonwealth efforts shifted the Rann of $K u t c h$ dispute from the military to the arbitral arena.

Fundamental international norms recognize the primary security right of regional organizations. A judgment-creditor planning an enforcement action alone or in concert with other states may seek to gain a preliminary authorization from the relevant regional organization. This strategy is particularly desirable when an authorization procedure will be blocked in the United Nations.

4. Nation-states: Nation-states, the primary repositories of effective power, are the most promising candidates for functional enforcement. Although a disinclination to become involved in the affairs of others prevails, the duty to aid in enforcing community decisions is a "general principle of law." The Treaty of Washington and the Alabama are clear holdings that failure to prevent another's noncompliance with international law is, itself, a delict against the state suffering the original breach. Subsequent American practice is consonant with this principle.

Judicial Action: If assets of the target state are found in state $X$, it may be possible to employ $X$ 's courts to enforce the international judgment. Certain writers have asserted that national enforcement of ICJ judgments is a principle of customary international law. Yet the leading case is somewhat equivocal. In Socobel, an award gained by a Belgian company against the Greek Government was subsequently upheld by the Permanent Court. In 1950, Socobel instituted garnishment proceedings against moneys owing to the Greek Government in Belgium, on the basis of the international judgment. The Belgian Tribunal Civil assimilated the PCIJ judgment to all other foreign judgments, refusing execution de plano. Municipal judicial enforcement is not excluded by this holding, neither is it facilitated by it.

Joint Executive Action: The coordinated action of several national executives may be an effective enforcement strategy. The impact of freezing assets, attachment, cessation of aid, severance of diplomatic relations and trade blockades can be compounded if undertaken multilaterally. Moreover, coordinated enforcement augments the authority of the action. Authorization can be increased by incorporating an organization. Thus, 
several states might initiate an interpleader action with the ICJ. The Statute makes no express provision for such procedure and the Court will probably disseise jurisdiction if the target state refuses to join issue. Therefore, the joint interpleader must be expressly contingent on the target's submission to jurisdiction. If the target submits, the other states agree to abide by the decision. If the target refuses to submit, the other parties will transfer the attached assets to the original judgment-creditor. There is a rough-hewn precedent for this procedure. After Albania impugned the Corfu Channel judgment, the Allied Powers asked the Court to determine whether monetary gold taken from Rome was Albanian. If it were, the parties agreed to transfer it to the United Kingdom in fulfillment of Corfu.

Unilateral Executive Action: Many of the strategies discussed above may be taken unilaterally. The fact that they are employed in judgmentenforcement will probably render them lawful. Unilateral action is subject to retaliation in kind, a danger minimized in joint action. Unilateral force should, when possible, be sanctioned by an organization prior to application.

5. Private Action: The automatic responses of individuals to an impugned judgment may conceal a sanction potential. Expectations of stability, upon which international economic interaction depends, are shaken by a challenge to global authority. Transnational commerce tends to flee from instability. Thus, the effect of noncompliance may be an instinctive commercial and economic withdrawal, which imposes a serious deprivation upon the impugning state. The aggregate international securities market is a rather reliable index of investor perspectives. When the U.S.S.R. arranged a patently corrupt arbitration award against Jordan Petroleum of Israel, the international credit status of Russia fell. The U.S.S.R. was subjected to a short-term sanction. Private sanctions may be intensified and sustained by publicly communicating an intention to pursue enforcement action. This, in turn, may engender voluntary compliance.

Functional enforcement is not an end in itself but a means for (1) securing present compliance with international law and (2) generating expectations of effectiveness ultimately crucial to the formation of a centralized enforcing authority. To this dual end, the following five principles should be brought to bear upon every enforcement move.

1. Substitutive Enforcement. The objects of numerous international disputes often remain in the control of the losing party. Seizing and transferring them may require a degree of force which is impractical. In an increasingly interdependent world, control over other assets of any state is often divided among a number of other states. Given a scale of equivalences, such as that of international commerce, substitutes can be found in lieu of the original object of the dispute. Substitution should be sought insofar as it reflects the subjective valuation of the litigants.

2. Anticipatory Enforcement. Although fixed-and-flow resources may be valuated, they enjoy a primacy among nation-states which does not 
admit of substitution. Moreover, in certain nonterritorial disputes, the winning litigant may gain substituted enforcement, yet the loser, by retaining the subject of litigation, frustrates the attempted resolution of the conflict. Hence, provision should be made for anticipatory enforcement. Administrative control of the territory in dispute could be transferred to an international authority while the matter was $s u b$ judice. On a more modest scale, the forces of the occupying litigant could be evacuated during proceedings. Provisions such as these must be made in the compromis. In nonterritorial disputes, earnest may be prepaid into court. Where liquidity problems or restricted monetary policies make this unfeasible, the compromis may make elaborate provision for garnishment; third party debtors should be privy to a separate protocol. Alternatively, protocols can arrange liens on national funds held by international banks and development organizations.

3. Expeditious Enforcement. An enforcement system is ultimately grounded upon the expectation that the system worlss. A lag between judgment and enforcement tends to diminish this expectation and to increase resistance to voluntary compliance. Enforcement strategies, devised pendente lite, should be launched promptly. If only moderate resistance to compliance is anticipated, the preferred strategy may be one which, though not optimum, is the quickest demonstration of intention. Dispatch can also prevent domestic politicization of compliance decisions.

4. Avoid Coercive Indirect Enforcement. Enlightened self-interest as well as humanitarianism militate against coercive strategies. It is a commonplace that violence is contagious. Moreover, unilateral military action ean trigger escalation. Coercion rarely resolves disputes; more often it deepens the rancor and hostility of both parties. Paradoxically, proponents of peace, who genuinely abhor violence, must at times resort to it in order to protect the principles and institutions they cherish. There will undoubtedly be instances in which highly coercive strategies alone promise success, but they should be employed only as a last resort.

5. Community Participation. Although international self-help measures are not inherently unlawful, an enforcement program, particularly one coercive in nature, should draft as wide a participation as possible. A united community tends to isolate the defaulting party, to magnify its unlawful act and to lend a corporate sanction to any indirect action. It emphasizes responsible commitment to the validity of judgments and creates an image of integrated enforcement.

International enforcement is neither impossible, nor so difficult and uneconomical as to be unfeasible. Even were it so, the lawyer could not claim discharge from the burden of dealing with it. Law, in any socially significant sense, requires that there be, at the bare minimum, an expectation of effectiveness, if not a point-for-point correlation between decision and allocation. Creating and sustaining that expectation is a basic legal function.

Effective law does not depend exclusively on operating enforcement mechanisms. In the most fundamental sense, it depends upon a compre- 
hensive grasp of legal and social process as well as consideration, in the performance of each legal function, of its relation to and impact on all the others. Thus, for example, the adjudicative phase will not produce a highly unenforcable decision; the preseriptive phase will consider an appropriate timetable for its programs and, hence, avoid ineffectiveness and so on. Yet, the crucial rôle of enforcement must be accepted, its concern to the lawyer confirmed and the inadequacies of its current conceptualizations conceded. The development of a viable enforcement system will be a delicate complicated process which will require a long and arduous period of application before a high degree of conformity with international law can be expected as a matter of course. But it must be undertaken. A right without a remedy, as Justice Holmes said, is no right at all. An international law system which deems itself so incapable of effective decision that it must retreat from the most critical cases cannot meet the requirements of a world community increasingly in need of legal order.

The first commentator was Mr. Cladde ChayeT, the Deputy Permanent Representative of France to the United Nations. Mr. CHayer began his remarks by noting that in a room full of lawyers he felt more comfortable by claiming to be a diplomat rather than a lawyer. As a diplomat, he quipped, he can claim to be a generalist and thereby protect his ignorance.

Mr. CHAYET said he would like to take a practical approach to the matter. He pointed out that the scope of each of the principal addresses was different. Mr. Reisman confined himself to judgments of tribunals. He said it was interesting to note that the International Court of Justice had promulgated 23 judgments in 23 years; the Permanent Court of Arbitration had pronounced 31 judgments in 50 years; between these two principal international tribunals there had been only three judgments every two years. Mr. CHAYET thought these figures give us a better perspective on the scope of the problem. Thus, the problem of enforcement is a limited one. In addition, the following factors further limit the scope of the problem: (1) the binding nature of the decisions; (2) methods of enforcement have been agreed upon in advance; (3) the consequences of enforcement have been weighted by each state prior to submission.

Mr. ChaYeT noted that he had taken part in seven cases before international tribunals and there had not been any significant problems of enforcement. If the problem of enforcement of IGJ decisions were to be submitted to the General Assembly he felt that the matter would arouse little interest since the question was neither urgent nor of practical importance.

On the other hand, Mr. Sloan's interesting survey of the implementation and enforcement of decisions of other international organizations has a much broader scope. He noted that the nature of the decisions varies greatly as evidenced by the operative language such as reminds, urges, calls upon, is deeply concerned, emphasizes, reassures, condemns, et cetera. Such terminology often results from lengthy negotiations within the body taking the decision. It is the U.N. Charter, of course, which determines the question of whether a decision has binding force. 